\title{
Measures to reduce dynamic plunge pool pressures generated by a free jet
}

\author{
Th. Berchtold \\ Laboratory of Hydraulics, Hydrology and Glaciology (VAW), ETH Zurich, Zurich, Switzerland
}

M. Pfister

Laboratory of Hydraulic Constructions (LCH), Ecole Polytechnique Fédérale de Lausanne (EPFL), Lausanne, Switzerland. Formerly: VAW, ETH Zurich

\begin{abstract}
Spillways often include a flip bucket as terminal energy dissipator, combined with a plunge pool. To prevent scour at the river bed for large jet fall heights additional measures are required, such as terminal chute widening or increase of the plunge pool depth. The effect of these measures was investigated in hydraulic modeling. The dynamic plunge pool bottom pressures in the jet footprint area were systematically recorded. Both, the time-averaged and the fluctuating dynamic pressure heads are considered as references for the jet scour potential, beside the related pressure coefficients. The investigated measures were proven to be effective in terms of reduced pressures, especially in combination. The relevant parameters of the herein presented measures were systematically varied. This research relates to the Kárahnjúkar spillway model investigation, in which the principal working conditions as canyon topography, jet fall head and discharge spectrum were determined.
\end{abstract}

\section{INTRODUCTION}

Most reservoirs include a spillway to convey floods, thereby avoiding dam overtopping. They typically spill extreme discharges with a large head, resulting in high-velocity flows. Chute flows have a considerable energy at the spillway end, which has to be adequately dissipated upstream of the receiving waters (Fiorotto \& Rinaldo 1992, Lopardo 1988, Puertas \& Dolz 2005, Khatsuria 2005). Otherwise, large scour emerges which may destabilize the dam foundation or erode adjacent valley flanks, and generate sediment deposits further downstream. High-head spillways therefore often include a flip bucket with a plunge pool (Vischer \& Hager 1998).

Despite of jet disintegration and diffusion within the plunge pool (Ervine et al. 1997), jets may provoke unacceptable scour for a large fall height combined with a limited plunge pool depth (Bollaert \& Schleiss 2003a, b). Additional measures are then necessary to enhance the jet disintegration process, thereby minimizing its energy entrainment into the plunge pool (Ervine \& Falvey 1987, Annandale 2005, Bollaert \& Schleiss 2005, Pagliara et al. 2006, Li \& Liu 2010). These additional measures normally include elements to increase jet turbulence, such as terminal spillway width increase to generate thinner jets. Jet disintegration, spreading and aeration are thereby enhanced (Canepa \& Hager 2003, Schmocker et al. 2008, Pfister \& Hager 2009), reducing specific energy density at the jet footprint on the plunge pool bottom. Ervine et al. (1997) mention that jet diffusion in the plunge pool is furthermore relevant for limited pressure fluctuations on the pool bottom, and that air entrained by the jet reduces bottom pressure amplitudes. Manso et al. (2007) show that dynamic pressures at the bottom of shallow and deep pools often follow a Gaussian distribution.

This research presents measures affecting a free jet issued from a spillway to reduce plunge pool pressures. The results were derived from a physical model investigation conducted at the Laboratory of Hydraulics, Hydrology and Glaciology (VAW), ETH Zurich. This project was initiated by the related Kárahnjúkar spillway investigation (VAW 2006, Pfister et al. 2008), in 
terms of topography, net fall head and discharge spectrum. However, the relevant parameters of this work were systematically varied in a wide range, independent of the original project.
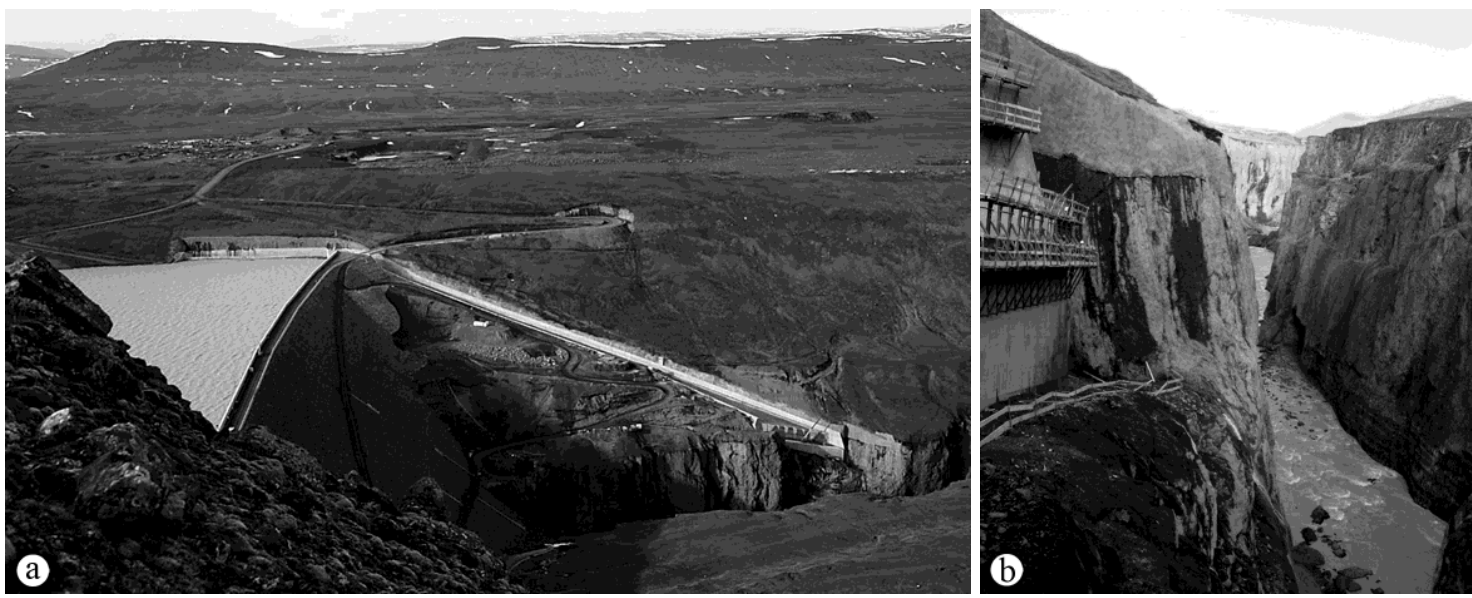

Figure 1. (a) Overview of Kárahnjúkar Dam and spillway above canyon (courtesy Landsvirkjun), and (b) canyon in flow direction with chute end at left; tailwater dike was not yet constructed.

The national power company of Iceland, Landsvirkjun, took the 690 MW Kárahnjúkar Hydroelectric Project in Eastern Iceland in 2008 into service for the electric supply of an aluminium smelter. It includes three dams storing the Hálslón reservoir with a water volume of $2.1 \cdot 10^{9} \mathrm{~m}^{3}$. An unregulated spillway is located at the left embankment of the $198 \mathrm{~m}$ high main dam (Fig. 1a), consisting of a side channel, a transition bend and a $419 \mathrm{~m}$ long chute. It was designed for a discharge of $1350 \mathrm{~m}^{3} / \mathrm{s}$, and evacuates a PMF of $2250 \mathrm{~m}^{3} / \mathrm{s}$ (Tómasson et al. 2006). At the chute end, the water falls as a free jet into a narrow canyon with almost $100 \mathrm{~m}$ high vertical rock flanks (Fig. 1b). These are unstable due to cracks and soft rock, such that measures to reduce the scour potential of the jet were sought. A tailwater dike resistant to overflow erosion stores a plunge pool on the riverbed.

\section{CHARACTERISTIC PLUNGE POOL PRESSURES}

The following pressure heads in [m] water column are considered:

- Effective (subscript $e$ ) measured, instantaneous (subscript $i$ ) transmitter pressure head $P_{e i}$.

- Hydrostatic pressure head $Y$ defined as vertical elevation difference between the transmitterlevel and tail water dike crest. This simplification overlooks the high degree of turbulence and air entrainment within the plunge pool which inhibits the recording of a precise hydrostatic pressure head.

- Dynamic (subscript $d$ ) instantaneous pressure head $P_{d i}=P_{e i}-Y$.

- Time-averaged (subscript $a$ ) dynamic pressure head $P_{d a}$ and respective average dynamic pressure coefficient $C_{d a}$ as

$$
\begin{aligned}
P_{d a} & =\frac{\sum P_{d i}}{N} \\
C_{d a} & =P_{d a}\left(\frac{v_{j}^{2}}{2 g}\right)^{-1}
\end{aligned}
$$

with $N$ as number of pressure head records, and $g$ as acceleration of gravity. The jet impact velocity $v_{j}$ on the plunge pool water surface was derived from the hydraulic model using highspeed particle tracking and from energy considerations. 
- Fluctuating dynamic pressure head $P^{\prime}{ }_{d}$ and respective fluctuating dynamic pressure coefficient $C_{d}^{\prime}$ as

$$
\begin{aligned}
P_{d}^{\prime} & =\sqrt{\frac{\sum\left(P_{d a}-P_{d i}\right)^{2}}{N}} \\
C^{\prime}{ }_{d} & =P^{\prime}{ }_{d}\left(\frac{v_{j}^{2}}{2 g}\right)^{-1}
\end{aligned}
$$

\section{HYDRAULIC MODEL}

The physical model was built for the Kárahnjúkar investigation with a scale factor of 45 and operated using Froude similitude (Fig. 2a, VAW 2006). It reproduced a sector of the Hálslón reservoir, the entire spillway, a section of the canyon and the complete plunge pool including the tailwater dike. The canyon bed was rigid, i.e. no scour occurred in the model thereby allowing for dynamic pressure measurements. The vertical extension of the Kárahnjúkar plunge pool depth is limited because: (1) plunge pool bottom elevation is restricted to avoid extensive excavation works and instability of the adjacent rock flanks, and (2) high water levels are excluded to avoid a submerged bottom outlet. The plunge pool width is 70 to $90 \mathrm{~m}$ restricted by the canyon dimensions (Figs 1-2), and its length is some $400 \mathrm{~m}$. The main dam toe is located $250 \mathrm{~m}$ upstream and the tailwater dike $150 \mathrm{~m}$ downstream of the jet impact. Given the narrow canyon and high discharges, a distinctive longitudinal flow component is established in the plunge pool toward the tailwater dike.

The take-off lip at the chute end is oblique relative to the flow direction, following the canyon edge. Furthermore, no flip bucket is installed, such that the chute end has the same slope of $20 \%$ as the chute. Beside constructional advantages, this design rotates the jet foot-print and adjusts it to the plunge pool shape (Pfister et al. 2008).
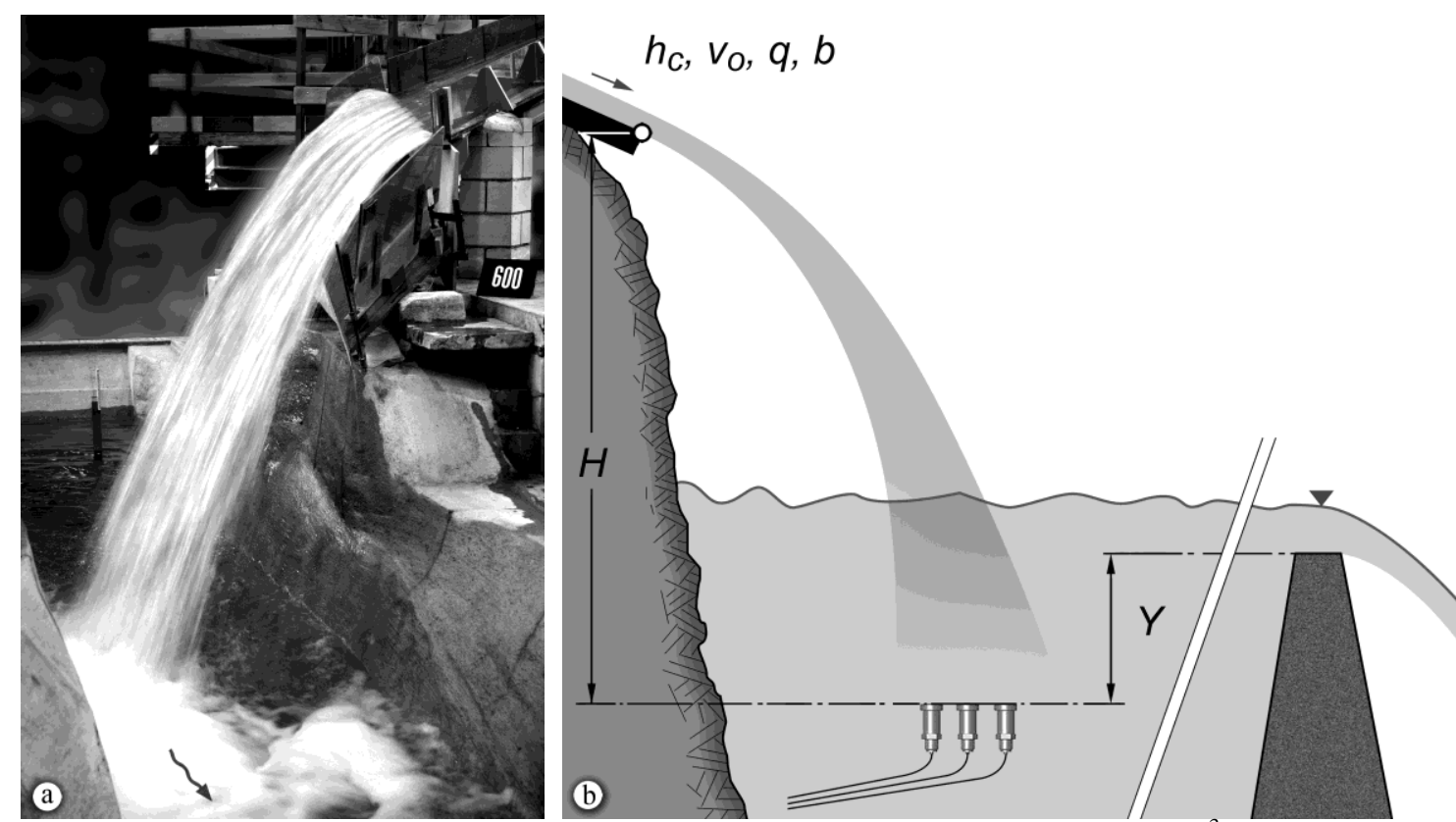

Figure 2. (a) Lower part of model spillway with canyon and plunge pool, $Q=600 \mathrm{~m}^{3} / \mathrm{s}, b=30.6 \mathrm{~m}$ and $Y=5.2 \mathrm{~m}$, and (b) definition plot. 
Table 1. Test program with systematic parameter variation including Tests $1-27$, and Tests $28-30$ related to Kárahnjúkar project, all in prototype dimensions.

\begin{tabular}{llllllllllllll}
\hline \multicolumn{2}{l}{ Test Nr. } & 1 & 2 & 3 & 4 & 5 & 6 & 7 & 8 & 9 & 10 & 11 & 12 \\
\hline$Q$ & {$\left[\mathrm{~m}^{3} / \mathrm{s}\right]$} & 400 & 600 & 800 & 400 & 600 & 800 & 400 & 600 & 800 & 400 & 600 & 800 \\
$b$ & {$[\mathrm{~m}]$} & 17.0 & 17.0 & 17.0 & 17.0 & 17.0 & 17.0 & 17.0 & 17.0 & 17.0 & 23.8 & 23.8 & 23.8 \\
$Y$ & {$[\mathrm{~m}]$} & 5.2 & 5.2 & 5.2 & 10.2 & 10.2 & 10.2 & 15.2 & 15.2 & 15.2 & 5.2 & 5.2 & 5.2 \\
$P_{d a M}$ & {$[\mathrm{~m}]$} & 15.3 & 19.5 & 21.3 & 7.4 & 9.2 & 13.5 & 2.6 & 5.1 & 10.5 & 12.8 & 15.7 & 18.8 \\
& & & & & & & & & & & & & \\
\multicolumn{2}{l}{ Test Nr. } & 13 & 14 & 15 & 16 & 17 & 18 & 19 & 20 & 21 & 22 & 23 & 24 \\
\hline$Q$ & {$\left[\mathrm{~m}^{3} / \mathrm{s}\right]$} & 400 & 600 & 800 & 400 & 600 & 800 & 400 & 600 & 800 & 400 & 600 & 800 \\
$b$ & {$[\mathrm{~m}]$} & 23.8 & 23.8 & 23.8 & 23.8 & 23.8 & 23.8 & 30.6 & 30.6 & 30.6 & 30.6 & 30.6 & 30.6 \\
$Y$ & {$[\mathrm{~m}]$} & 10.2 & 10.2 & 10.5 & 15.2 & 15.2 & 15.2 & 5.2 & 5.2 & 5.2 & 10.2 & 10.2 & 10.2 \\
$P_{d a M}$ & {$[\mathrm{~m}]$} & 3.8 & 7.5 & 8.3 & 2.4 & 3.2 & 4.5 & 8.1 & 11.9 & 13.3 & 2.6 & 5.2 & 7.6 \\
\multicolumn{2}{l}{ Test Nr. } & 25 & 26 & 27 & & 28 & 29 & 30 & & & & & \\
\hline$Q$ & {$\left[\mathrm{~m}^{3} / \mathrm{s}\right]$} & 400 & 600 & 800 & & 600 & 950 & 950 & & & & & \\
$b$ & {$[\mathrm{~m}]$} & 30.6 & 30.6 & 30.6 & & 30.6 & 30.6 & 30.6 & & & & & \\
$Y$ & {$[\mathrm{~m}]$} & 15.2 & 15.2 & 15.2 & & 6.5 & 6.5 & 11.5 & & & & & \\
$P_{d a M}$ & {$[\mathrm{~m}]$} & 2.4 & 2.5 & 3.1 & & 12.7 & 12.0 & 3.4 & & & & & \\
\hline
\end{tabular}

The discharge was determined by Inductive Discharge Measurement to $\pm 3 \%$ accuracy. The pressure head $P_{e i}$ was recorded in the model using transmitters, typically over $120 \mathrm{~s}$. BAUMER relative sensors were used for pressure measurements. These sensors have a flush-mounted diaphragm of diameter $17.5 \mathrm{~mm}$ with a relative measurement range between 0 and 1 bar and a precision of $\pm 0.5 \%$ of the full scale output. The sampling rate during dynamic acquisitions was $200 \mathrm{~Hz}$ and the transmitters were calibrated before each test. A movable plate with eight transmitters was fixed on the river bed to detect jet-generated pressures and their fluctuations. The entire jet footprint was thereby covered with a prototype grid spacing of $2.25 \mathrm{~m}$.

The width $b$ of the chute end perpendicular to the flow direction was varied between 17.0 and $30.6 \mathrm{~m}$, the hydrostatic plunge pool pressure head $Y$ between 5.2 and $15.2 \mathrm{~m}$, the discharge $Q$ between 400 and $800 \mathrm{~m}^{3} / \mathrm{s}$, and the jet impact head $H$ as elevation difference between the jet take-off level and the transmitter-level was kept constant at $92.5 \mathrm{~m}$, all in prototype dimensions (Fig. 2b). Small discharges as compared to PMF were tested to keep the footprint on the riverbed, thereby avoiding an effect of the canyon flanks. Discharges are expressed with the critical flow depth $h_{c}=\left(q^{2} / g\right)^{1 / 3}$, where $q=Q / b$. In total, 27 tests were conducted with $1.1 \leq b / Y \leq 5.9$ and $0.2 \leq h_{d} / Y \leq 1.2$. The present results therefore by far exceed the test program of the original spillway investigation including a systematic parameter variation, as noted from the test program (Table 1, Tests 1-27). Test series were conducted by varying one parameter, e.g. $Q$, and keeping the other two parameters constant, e.g. $b$ and $Y$. As a consequence, the isolated effect of each parameter on $P_{d a}$ resulted. Furthermore, selected tests of the Kárahnjúkar investigation (Tests 28-30) were considered with $Q$ up to $950 \mathrm{~m}^{3} / \mathrm{s}$, yet with isolated pressures affected by the opposite rock flank and the chute aerator, such that these were excluded for the data analysis.

\section{JET FOOTPRINT}

The grid for pressure measurements on the riverbed covered the entire canyon width, i.e. the entire jet footprint as the zone of notable jet-induced dynamic pressures. To define the footprint area, two criteria were applied: (1) $P_{d a} / H \geq 0.1 h_{c} / Y$, and (2) $P_{d a} \geq 2.0 \mathrm{~m}$ in absolute terms for model measurement reasons. The pressure head of criterion (1) corresponds to half of the maximum value detected within the footprint, as shown below. Transmitters whose measured heads satisfied both criteria were considered located within the jet footprint. The two criteria resulted from an extensive data analysis; absolute offset values as a function of e.g. $H$ resulted in poorlydefined footprint areas, especially for tests with small $Q$ and large $b$ and $Y$. 
Figure 3 shows an example of three footprints, where $b$ was varied, for otherwise constant parameters. The streamwise axis $x$ corresponds to the chute centre line, with the transverse coordinate $y$ perpendicular to $x$. Note that the footprint spreads with increasing $b$, is $\mathrm{U}$-shaped and relevant pressures are concentrated laterally. The U-shaped footprint originates from a slightly smaller lateral chute velocity due to wall friction, with a reduced jet take-off velocity generating shorter lateral jet trajectories as compared to the chute centre flow. The relative thickness of a narrow jet is larger than of a wide, such that the footprint concentrates near the chute axis around $y=0$. In contrast, the jet is thinner for a wide chute end, such that the footprint locally even disappears close to $y=0$. In parallel, small chute flow depths imply higher energy losses, such that the jet take-off velocity slightly decreases, shifting the footprint towards the chute end.

The individual $P_{d a}$ of all transmitters located within the footprint were summed up to $\Sigma P_{d a}$ and divided by the transmitter number $n$ located within the footprint. The data were then normalized with the jet impact head $H$ and plotted versus $h_{c} / Y$. Consequently, the footprint areaaveraged dynamic pressure head is

$$
\frac{\sum P_{d a}}{n H}=0.15 \frac{h_{c}}{Y} \quad \text { for } 0<h_{c} / Y<1.2
$$

with a coefficient of determination of $R^{2}=0.95$ between the model data and Eq. (5). The lower limit was set to $h_{c} / Y=0$, whereas the data only include $h_{c} / Y \geq 0.17$, because $P_{d a}\left(h_{c} / Y \rightarrow 0\right) \rightarrow 0$. Figure 4 compares the measured data with Eq. (5). Note that the footprint is located close to the opposite canyon flank for large discharges. Then, a distinction between footprint and wall effect was difficult, such that unfiltered data may include small wall effects in Eq. (5).
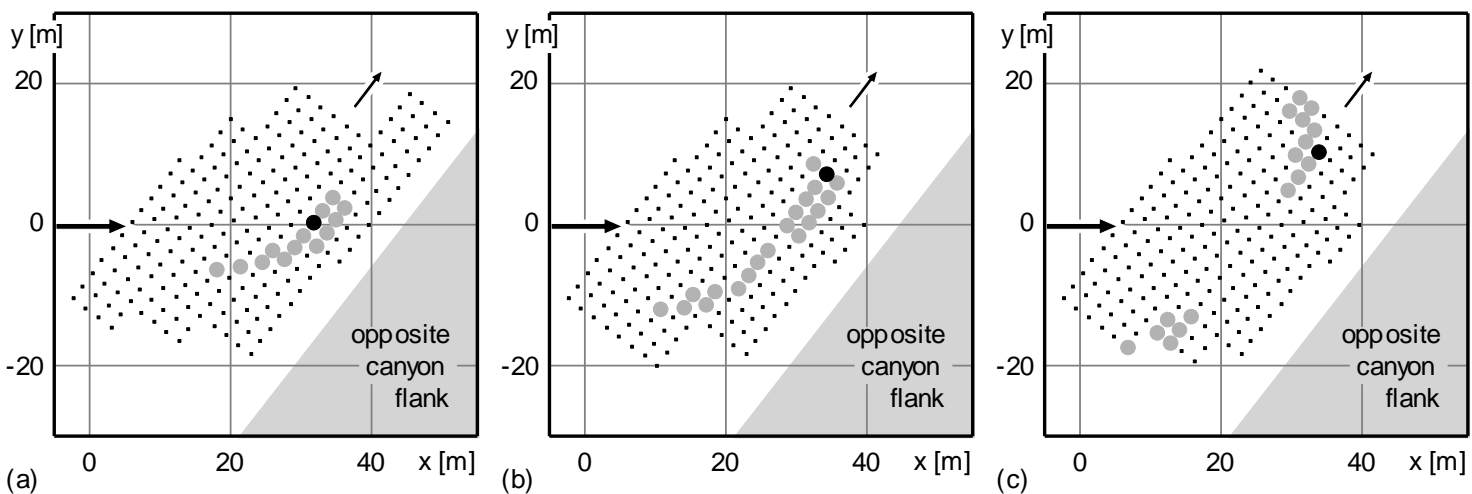

Figure 3. Footprint example of Tests (a) 3, (b) 12 , and (c) 21, i.e. for increasing $b$, with (.) transmitter location, ( $\bullet$ ) footprint area, and $(\bullet)$ maximum $P_{d a M}$.

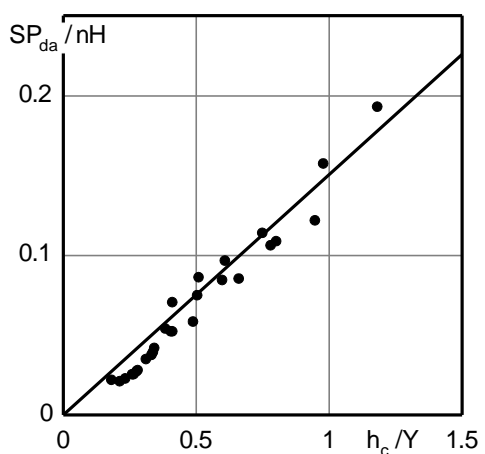

Figure 4. Footprint area-averaged dynamic pressure head $\Sigma P_{d a} / n H\left[h_{c} / Y\right]$ with (-) Eq. (5).

\section{EFFECTS OF CHUTE END WIDTH, DISCHARGE AND PLUNGE POOL DEPTH}

\subsection{Individual effect}

The characteristic pressure heads $P_{d a}$ were derived for all grid points, of which the maximum (subscript $M$ ) $P_{d a M}$ within the footprint area was selected for further analysis to investigate the 
effects of $b, Q$, and $Y$. The long chute upstream of the take-off generates fully developed turbulent approach flow with uniform flow conditions for the tested discharges. The measured average maximum $P_{d a M}$ of all tests was $21.3 \mathrm{~m}$ (Table 1), corresponding to $23 \%$ of $H$. This is a relatively small value, pointing at pronounced jet disintegration. Almost immediately beyond takeoff, the jet is fully-aerated below some 3 to $7 \%$ of $H$ (Pfister \& Hager 2009), and breaks up at 14 to $22 \%$ of $H$ (Ervine et al. 1997), reducing pressures drastically in the plunge pool.

Figure 5 shows the un-normalized isolated effects of $Q, Y$, and $b$ on $P_{d a M}$ in prototype dimensions. Within a series consisting of three tests, only the discussed parameter varies, while the others remain unchanged. Note from Figure 5a that $P_{d a M}$ almost linearly increases with $Q$. However, this effect is relatively small, as $P_{d a M}$ only slightly increases with $Q$. More relevant is $Y$ (Fig. 5b), involving a strong decrease of $P_{d a M}$ for large $Y$, similar to Ervine et al. (1997). The effect of $b$ on $P_{d a M}$ is shown in Figure 5c, indicating reduced pressures as $b$ increases. The maximum time-averaged dynamic pressure head $P_{d a M}$ measured within the jet footprint therefore increases with discharge, but decreases with chute end width, and with deep plunge pools. The jet impact head $H$ further affects plunge pool pressures, yet this parameter was kept constant herein.
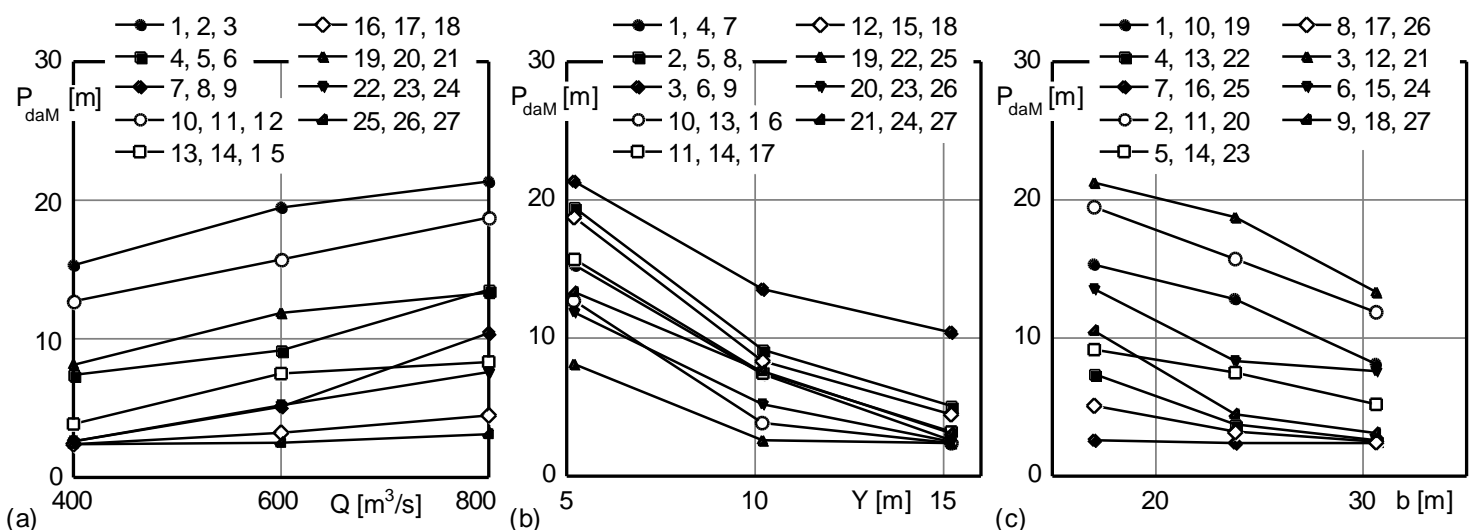

Figure 5. Individual effect of (a) $Q$, (b) $Y$, and (c) $b$ on $P_{d a M}$, test number according to Table 1 .

\subsection{Normalized results}

The dynamic plunge pool pressures were normalized as $P_{d a M} / H$ and $P_{d M}^{\prime} / H$ to include the jet impact head (Khatsuria 2005). The additionally investigated parameters affecting the plunge pool pressures were normalized as $h_{d} / Y=\left[(Q / b)^{2} / g\right]^{1 / 3} Y^{-1}$ thereby including $Q, b$ and $Y$. The model data of $P_{d a M}$ collapse with a linear trend line as (Fig. 6a)

$$
\frac{P_{d a M}}{H}=0.20 \frac{h_{c}}{Y} \quad \text { for } 0<h_{c} / Y<1.2
$$

with $R^{2}=0.93$ between the model data and Eq. (6). The latter may be expressed as $P_{d a M}=0.2 H Y^{-1} Q^{2 / 3} b^{-2 / 3} g^{-1 / 3}$ to assess the effect of the single variables, indicating that the jet impact head $H$ and the plunge pool depth $Y$ are significant, whereas the chute end width $b$ and the discharge $Q$ are less relevant. Dividing Eq. (5) by Eq. (6) results in $\left(\Sigma P_{d d} / n\right) / P_{d a M}=0.75$. Accordingly, the area-averaged footprint pressure head is equivalent to some $75 \%$ of the local maximum $P_{d a M}$, independent of $b, Q$ and $Y$. The individual measured data include a ratio of 60 to $100 \%$, with an average around $77 \%$.

The same abscissa normalization as for $P_{d a M}$ was used for $P_{d M}^{\prime}$, again resulting in a linear trend as

$$
\frac{P_{d M}^{\prime}}{H}=0.23 \frac{h_{c}}{Y}-0.03 \quad \text { for } 0<h_{c} / Y<1.2
$$

Figure $6 \mathrm{~b}$ compares the data and Eq. (7), with $R^{2}=0.89$. Note that $P_{d M}^{\prime} / H=0$ for $h_{d} / Y<0.13$. Accordingly, fluctuating pressures are absent if $h_{c}$ is sufficiently small, i.e. for a small $q$ com- 
bined with large values $Y$ corresponding to 'deep' plunge pools, resulting in small $P_{d a M}$, combined with $P_{d M}^{\prime}=0$. The jet momentum affects the plunge pool bottom, while the jet fluctuations are fully damped by the water cushion.

As explained, $P_{d a M}$ refers to the transmitter with the maximum measured average value of the entire footprint. To ensure its relevance, the next smaller maxima M2 and M3 were considered, with M1 representing the maximum $P_{d a M}$, and M2 as well as M3 the next smaller values at a different transmitter. These are shown in Figure 6c, which corresponds basically to Figure 6a plus the further maxima. All values M1 to M3 almost collapse, such that recording errors may be excluded. In parallel, linear best fits were added to the figure, indicating a slight decay of the gradients for $\mathrm{M} 1 \rightarrow \mathrm{M} 3$. Accordingly, M2 and M3 are marginally lower than the absolute maximum M1.
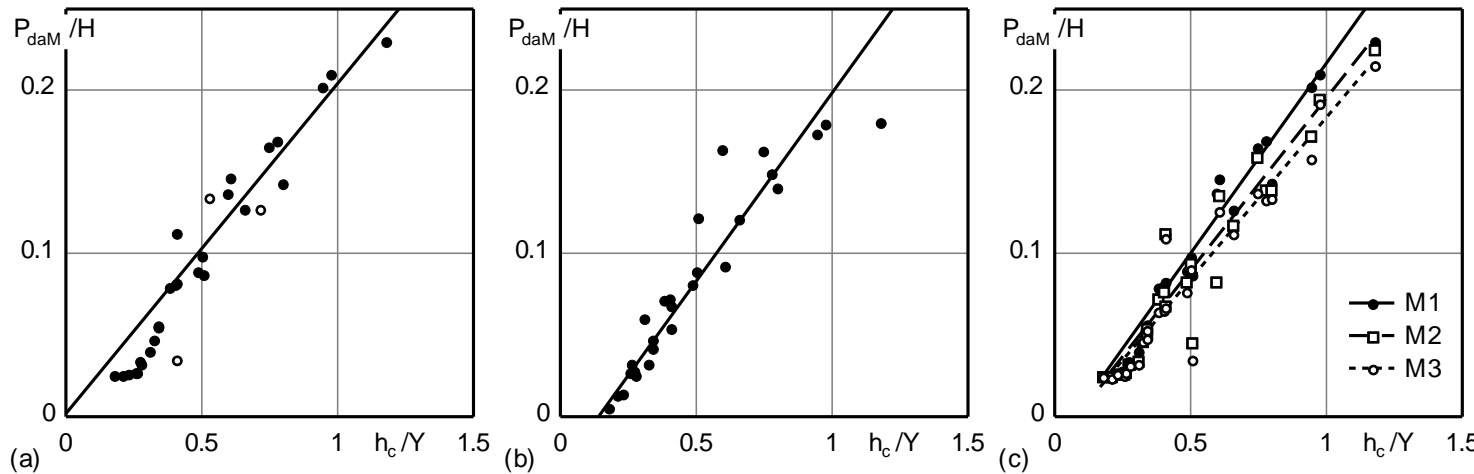

Figure 6. (a) $P_{d a M} / H\left[h_{c} / Y\right]$ with (-) Eq. (6) and (O) Tests 28-30, (b) $P_{d M}^{\prime} / H\left[h_{c} / Y\right]$ with (-) Eq. (7) and (c) maxima M1 to M3 of $P_{d a M} / H\left[h_{c} / Y\right]$ with trend lines.
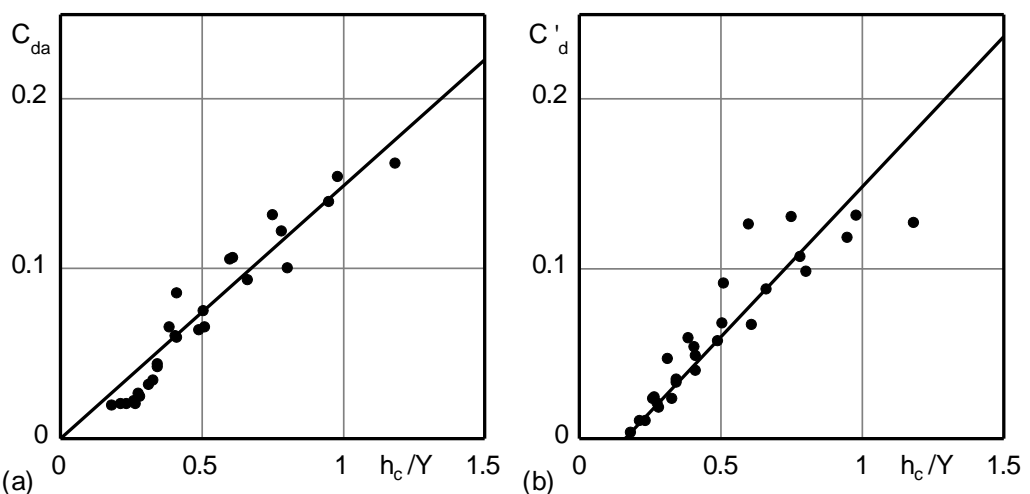

Figure 7. (a) $C_{d a}\left[h_{c} / Y\right]$ with (-) Eq. (8), and (b) $C_{d}\left[h_{c} / Y\right]$ with (-) Eq. (9).

The pressure coefficients were again derived as a function of $h_{c} / Y$. The dynamic coefficient collapses with a linear trend line as $\left(R^{2}=0.93\right)$.

$$
C_{d a}=0.15 \frac{h_{c}}{Y} \quad \text { for } 0<h_{c} / Y<1.2
$$

The fluctuating coefficient was expressed as $\left(R^{2}=0.84\right)$

$$
C^{\prime}{ }_{d}=0.18 \frac{h_{c}}{Y}-0.03 \quad \text { for } 0<h_{c} / Y<1.2
$$

The data of both coefficients are shown in Figure 7 including Eqs. (8) and (9), indicating good agreement between measurements and predictions. Again, the fluctuating pressure coefficient is zero for $h_{c} / Y<0.13$, as the fluctuating pressure head was.

Dividing Eq. (8) by Eq. (6) results in $C_{d d} /\left(P_{d a M} / H\right)=0.75$. Accordingly, the dynamic pressures coefficients are $75 \%$ of the relative dynamic pressure head, independent of $b, Q$ and $Y$. From Eq. (2) then follows the jet net head $v_{j}^{2} / 2 g=1.3 \mathrm{H}$. For the present tests, the gross jet energy head at impact on the plunge pool water surface is $H$ plus the velocity head at take-off, 
which is between 0.3 and $0.5 \mathrm{H}$. Accordingly, the difference of the gross jet head equivalent to 1.3 to $1.5 \mathrm{H}$ and the net jet head with $1.3 \mathrm{H}$ ranges between 0 and $0.2 \mathrm{H}$, probably related with jet dissipation effects.

\section{CONCLUSION}

Measures to reduce dynamic plunge pool pressures generated by a free jet are discussed, including jet expansion by terminal chute widening and increase of the plunge pool depth. The effect of these parameters was investigated using a hydraulic model with a systematic parameter variation. The dynamic and fluctuating pressure heads on the plunge pool bottom were thereby considered as reference values. For the present case study, the jet impact head $H$ and the plunge pool depth $Y$ are relevant, whereas the chute end width $b$ and the discharge $Q$ are of lower significance. Equations were derived to predict the determining pressures within the limitations of the model investigation. The model limitations relate to the jet fall height, the discharge spectrum and the plunge pool arrangement, resulting from the Kárahnjúkar spillway investigation, for which the model was initially erected.

\section{REFERENCES}

Annandale, G.W. 2005. Scour technology. McGraw-Hill, New York.

Bollaert, E.F.R. \& Schleiss, A.J. 2003a. Scour of rock due to the impact of plunging high velocity jets Part I: A state-of-the-art review. Journal of Hydraulic Research 41(5), 451-464.

Bollaert, E.F.R. \& Schleiss, A.J. 2003b. Scour of rock due to the impact of plunging high velocity jets Part II: Experimental results of dynamic pressures at pool bottoms and in one- and two-dimensional closed end rock joints. Journal of Hydraulic Research 41(5), 465-480.

Bollaert, E.F.R. \& Schleiss, A.J. 2005. Physically-based model for evaluation of rock scour due to high velocity jet impact. Journal of Hydraulic Engineering 131(3), 153-165.

Canepa, S. \& Hager, W.H. 2003. Effect of jet air content on plunge pool scour. Journal of Hydraulic Engineering 129(5), 358-365.

Ervine, D.A. \& Falvey, H.T. 1987. Behavior of turbulent water jets in the atmosphere and in plunge pools. Proc. Instn Civ. Engrs 83(2), 295-314, Paper 9136.

Ervine, D.A, Falvey, H.T. \& Withers, W. 1997. Pressure fluctuations on plunge pool floors. Journal of Hydraulic Research 35(2), 257-279.

Fiorotto, V. \& Rinaldo, A. 1992. Turbulent pressure fluctuations under hydraulic jumps. Journal of Hydraulic Research 30(4), 499-520.

Khatsuria, R.M. 2005. Hydraulics of spillways and energy dissipators. Dekker, New York.

Li, A. \& Liu, P. 2010. Mechanism of rock-bed scour due to impinging jet. Journal of Hydraulic Research 48(1), 14-22.

Lopardo, R.A. 1988. Stilling basin pressure fluctuation. Proc. Intl. Symposium on Model-Prototype Correlation of Hydraulic Structures, Colorado Springs, USA, 56-73.

Manso, P.A., Bollaert, E.F.R. \& Schleiss, A.J. 2007. Impact pressures of turbulent high-velocity jets plunging in pools with flat bottom. Experiments in Fluids 42(1), 59-60.

Pagliara S., Hager, W.H. \& Minor, H.-E. 2006. Hydraulics of plunge pool scour. Journal of Hydraulic Engineering 132(5), 450-461.

Pfister, M., Berchtold, T. \& Lais, A. 2008. Kárahnjúkar dam spillway: Optimization by hydraulic model tests. 3rd IAHR International Symposium in Hydraulic Structures, Hohai University, Nanjing (Cn), VI, 2106-2111.

Pfister, M. \& Hager, W.H. 2009. Deflector-generated jets. Journal of Hydraulic Research 47(4), 466-475.

Puertas, J. \& Dolz, J. 2005. Plunge pool pressures due to a falling rectangular jet. Journal of Hydraulic Engineering 131(5), 404-407.

Schmocker, L., Pfister, M., Hager, W.H. \& Minor, H.-E. 2008. Aeration characteristics of ski jump jets. Journal of Hydraulic Engineering 134(1), 90-97.

Tómasson, G.G., Garðarsson, S.M., Petry, B. \& Stefánsson, B. 2006. Design challenges and solutions for the Kárahnjúkar spillway. Hydropower \& Dams 13(5), 84-88.

VAW 2006. Kárahnjúkar HEP Iceland; Physical model investigation on the Kárahnjúkar dam spillway. VAW Report 4203, ETH: Zurich [unpublished].

Vischer, D.L. \& Hager, W.H. 1998. Dam hydraulics. John Wiley \& Sons, Chichester, UK. 